\title{
Freshwater transport in the coupled ocean-atmosphere system: a passive ocean
}

Article

Accepted Version

Ferreira, D. and Marshall, J. (2015) Freshwater transport in the coupled ocean-atmosphere system: a passive ocean. Ocean Dynamics, 65 (7). pp. 1029-1036. ISSN 1616-7341 doi: https://doi.org/10.1007/s10236-015-0846-6 Available at https://centaur.reading.ac.uk/40161/

It is advisable to refer to the publisher's version if you intend to cite from the work. See Guidance on citing.

To link to this article DOI: http://dx.doi.org/10.1007/s10236-015-0846-6

Publisher: Springer Verlag

All outputs in CentAUR are protected by Intellectual Property Rights law, including copyright law. Copyright and IPR is retained by the creators or other copyright holders. Terms and conditions for use of this material are defined in the End User Agreement.

www.reading.ac.uk/centaur

\section{CentAUR}


Central Archive at the University of Reading

Reading's research outputs online 
Ocean Dynamics manuscript No.

(will be inserted by the editor)

1. Freshwater transport in the coupled

2 ocean-atmosphere system: a passive ocean

D. Ferreira - J. Marshall

5 Received: date / Accepted: date

6 Abstract Conservation of water demands that meridional ocean and atmo7 sphere freshwater transports (FWT) are of equal magnitude but opposite in 8 direction. This suggests that the atmospheric FWT and its associated latent

9 heat (LH) transport could be thought of as a "coupled ocean/atmosphere mode". But what is the true nature of this coupling? Is the ocean passive or 1 active?

Here we analyze a series of simulations with a coupled ocean-atmospheresea ice model employing highly idealized geometries but with markedly differ-

D. Ferreira

Dept. of Meteorology, Room 1U10, University of Reading,

PO Box 243, Reading, RG6 6BB, UK

E-mail: d.g.ferreira@reading.ac.uk

J. Marshall

Department of Earth Atmosphere and Planetary Sciences,

Massachusetts Institute of Technology

77 Massachusetts Avenue Cambridge MA 02139, USA 
14 ent coupled climates and patterns of ocean circulation. Exploiting streamfunc-

15 tions in specific humidity coordinates for the atmosphere and salt coordinates

16 for the ocean to represent FWT in their respective medium, we find that at-

17 mospheric FWT/LH transport is essentially independent of the ocean state.

${ }_{18}$ Ocean circulation and salinity distribution adjust to achieve a return freshwa-

19 ter pathway demanded of them by the atmosphere. So, although ocean and

20 atmosphere FWTs are indeed coupled by mass conservation, the ocean is a

${ }_{21}$ passive component acting as a reservoir of freshwater.

22 Keywords Freshwater transport · latent heat transport · hydrological cycle

\section{$23 \quad 1$ Introduction}

24 A large fraction of the Equator to Pole energy transport is achieved by the at25 mosphere through latent heat $(\mathrm{LH})$ transport — see for example the summary 26 in Marshall and Plumb (2008). In mid- to high-latitudes where the atmo${ }_{27}$ sphere dominates the total meridional energy transport, the LH contribution ${ }_{28}$ is as large or larger than the dry static energy transport (DSE, the sum of 29 sensible and potential energy fluxes). The LH flux is associated with a trans30 port of moisture from regions of net evaporation in the subtropics to regions 31 of net precipitation in the tropics and high-latitudes. In steady state, the 32 atmospheric moisture transport must be balanced by an equal but opposite 33 freshwater transport (FWT) by the oceans (neglecting small storage terms 34 and transport by rivers and sea ice). 
This constraint is the reason why the atmospheric LH transport is some-

36 times thought of as a "coupled mode of transport" (Rhines et al, 2008) $)^{1}$ or a

${ }_{37}$ "joint atmosphere-ocean process" (Bryden and Imawaki, 2001). For the same

38 reasons, Wijffels (2001) describes the oceanic FWT as a fundamental part of

39 the planetary energy budget. Such characterizations put the ocean, through

${ }_{40}$ its FWT, at the heart of the coupled ocean-atmosphere energy cycle. Is this

${ }_{41}$ justified? There is no doubt that the atmospheric LH transport and ocean

${ }_{42}$ FWT are related. It is the nature of this coupling between atmospheric LH

43 transport and ocean circulation that is the focus of attention of the present

44 study. Does the oceanic FWT constrain the working of atmospheric LH trans-

45 port ? Or is the ocean passive, i.e. is the coupling one-way? At a time when the

46 hydrological cycle is predicted to intensify (Held and Soden, 2006) and salinity

47 is already observed to be changing at the surface and at depth (Durack and

${ }_{48}$ Wijffels, 2010), it is important to clarify the nature of the relationship between

49 the two major components of the global hydrological cycle.

To the atmospheric scientist, the answer to the above question is obvious:

51 the atmospheric water cycle is driven by atmospheric processes and the ocean

${ }_{52}$ is a passive agent, providing the reservoir of water but little more. To many

53 oceanographers, the answer is less clear: the FWT is a truly coupled prob-

${ }_{54}$ lem with the ocean supplying both the freshwater and the heat required for

55 evaporation (among other arguments advanced below).

\footnotetext{
1 From Rhines et al (2008): "Latent heat is fresh water (2.4 PW per Sverdrup), and its transport is an intrinsically coupled ocean/atmosphere mode"
} 
This contribution is an attempt to bring some clarity to this discussion and

57 bridge the gap between the different perspectives. We hope it is a particular fit to this Special Issue on "Atmosphere and Ocean dynamics" in honor of Richard

59 Greatbatch, whose work over the years has made such important contributions

60 to our understanding of the two fluids and their interaction.

To address this question, we analyze a series of idealized simulations with 62 a coupled ocean-atmosphere-sea ice General Circulation Model (GCM). We 63 employ highly idealized geometries in which continents are reduced to narrow ${ }_{64}$ barriers. The sequence from Aqua to Ridge to Drake to Double-Drake can ${ }_{65}$ be regarded as a "cartoon" that increases the level of geometrical complexity ${ }_{66}$ (Fig. 1): from the pure Aquaplanet (where there are no topographic constraints ${ }_{67}$ on ocean circulation) to the Double-Drake (in which interhemispheric and 68 zonal asymmetries are present) — see Marshall et al (2007); Enderton and ${ }_{69}$ Marshall (2009). By changing the geometrical constraints, the sequence of 70 simulations switches in, one by one, key components of the ocean circulation $71 \quad$ (subtropical cells, gyres, zonal jets, inter-hemispheric meridional overturning 72 circulation (MOC), etc). Our simulations range across a wide spectrum of 73 climates, as illustrated by the variety of forms of the MOC shown in Fig. 2 74 (right). As shown by Ferreira et al (2010), when viewed through the lens of heat 75 and freshwater transport, the climate of Double-Drake exhibits an uncanny 76 resemblance to the real world, with, notably, the localization of deep water 77 formation in the Small basin only, in analogy with the contrasting circulations 78 of the Atlantic and Pacific basins of today's climate. 
A central result of our study is immediately apparent in Fig. 2. Although

so the ocean circulations of each coupled climate are very different - they have to

${ }_{81}$ be because the geometry of the ocean basins differs so markedly between them

${ }_{82}$ - the meridional FW transport hardly changes across the climate states. To

${ }_{83}$ probe meridional transports further we diagnose overturning streamfunctions

${ }_{84}$ in specific humidity $q$ and in salt $S$ coordinates for the atmosphere and ocean

${ }_{85}$ respectively. Such approaches have been widely used in the atmosphere and

${ }_{86}$ ocean, notably in studies of energy transports (e.g. Karoly et al (1997), Held

${ }_{87}$ and Schneider (1999), Pauluis et al (2008) for the atmosphere; Saenko and

88 Merryfield (2006), Lumpkin and Speer (2007), Ferrari and Ferreira (2011) for

89 the ocean; Czaja and Marshall (2006) for the coupled system). Their appeal

90 lies in the fact that they naturally include transports associated with standing

91 and transient eddies and directly relate to the net meridional transport. Here,

$92 \quad q$ - and $S$-coordinate streamfunctions reveal atmospheric and oceanic FWTs,

93 respectively, and elegantly illustrate the symmetry between the two FWTs

94 and their connection through Evaporation minus Precipitation (E-P).

We find that the dynamics of the oceanic FWT takes very different forms

96 under rather similar E-P patterns and argue that the atmospheric FWT and

${ }_{97}$ LH transports are largely independent of the ocean. That is, the "coupling" of

98 the atmospheric LH "mode" is primarily one-way with the ocean responding

99 passively to atmospheric dynamics.

Our paper is organized as follows. Section 2 briefly describes our coupled

GCM and the computation of tracer-based streamfunctions. In section 3, we 
investigate the $S$ - and $q$-coordinate streamfunction and show how it informs us about the dynamics of FWT and the symmetry between ocean and atmosphere FWT in the climate system. Conclusions are given in section 4 .

\section{Model and methods}

\subsection{The coupled GCM}

We use the MITgcm in a coupled ocean-atmosphere-sea ice set-up (Marshall et al, 1997a,b). All components use the same cubed-sphere grid at C24 resolution $\left(3.75^{\circ}\right.$ at the equator) (Adcroft et al, 2004). Both ocean and atmosphere are primitive equation models and are generated from the same dynamical core exploiting an isomorphism between ocean and atmosphere dynamics (Marshall et al, 2004).

The atmospheric physics is based on the SPEEDY scheme (Molteni, 2003) at low vertical resolution (5 levels). It comprises a 4-band radiation scheme, a parametrization of moist convection, diagnostic clouds and a boundary layer scheme. The 3-km deep, flat-bottomed ocean model has 15 vertical levels. Effects of mesoscale eddies are parametrized as an advective process (Gent and McWilliams, 1990) together with an isopycnal diffusion (Redi, 1982), both with a transfer coefficient of $1200 \mathrm{~m}^{2} \mathrm{~s}^{-1}$. Convective adjustment, implemented as an enhanced vertical mixing of potential temperature and salinity, is used to represent ocean convection (Klinger et al, 1996). The background vertical diffusion is uniform and set to $3 \times 10^{-5} \mathrm{~m}^{2} \mathrm{~s}^{-1}$. 
The sea-ice component is based on the Winton (2000) thermodynamic model (two layers of ice plus surface snow cover). The prognostic variables are ice fraction, snow and ice thickness, and a two-level enthalpy representation which accounts for brine pockets, employing an energy conserving formulation. obliquity of $23.5^{\circ}$, and zero eccentricity) but there is no diurnal cycle.

Finally, as discussed by Campin et al (2008), our coupled model achieves

The land model is a simple 2-layer model with prognostic temperature, soil moisture, run-off, and snow height. The atmospheric $\mathrm{CO}_{2}$ level is prescribed at present day values. The seasonal cycle of insolation is represented (using an

perfect (machine-accuracy) conservation of freshwater, heat and salt during extended climate simulations, a property which is crucial to the fidelity and integrity of the coupled system. This is made possible by the use of the rescaled height coordinate $\mathrm{z}^{*}$ in the ocean (Adcroft and Campin, 2004). Importantly here, this coordinate permits the use of real freshwater boundary conditions everywhere, including at the sea ice ocean interface. The set-up is identical to that used in Ferreira et al $(2010,2011)$, to which the reader is referred for further details.

All simulations used in this study were integrated for 5000 years or more and reached a statistical equilibrium. Diagnostics are based on 50-year averages. 
2.2 Tracer-based overturning

For each set of contemporaneous 3d flow field and tracer field $C$ (whether they are instantaneous or time-averaged fields), all meridional mass/volume fluxes $^{2}$ at a given latitude $\phi$ are first binned according to the value of $C$. One thus obtains a $2 \mathrm{~d}$ field $M(\phi, C)$ which contains the accumulated mass fluxes advecting tracer value between $C$ and $C+d C$ at latitude $\phi$. The streamfunction in the $C$-coordinate is then computed as:

$$
\Psi(\phi, C)=-\int_{C_{m i n}}^{C} M(\phi, C) d C,
$$

where $C_{\min }$ is the minimum value of the tracer. The unit of $\Psi$ is the Sverdrup which is equal to $10^{6} \mathrm{~m}^{3} \mathrm{~s}^{-1}$ in the ocean and, as in Czaja and Marshall (2006), to $10^{9} \mathrm{~kg} \mathrm{~s}^{-1}$ in the atmosphere (equivalent to the mass transport of an oceanic Sv, $\left.\sim 10^{3} \mathrm{~kg} \mathrm{~m}^{-3} \times 10^{6} \mathrm{~m}^{3} \mathrm{~s}^{-1}\right)$. The integral of the tracer-coordinate streamfunction over the full tracer range is equal to the net advective meridional transport of the tracer. [In our ocean model, the total transport also has a small diffusive contribution due to the horizontal component of the isopycnal diffusion.] In the following, we denote the $C$-coordinate overturning by $\Psi(C)$.

In the atmosphere, the DSE and LH are given by $C_{p a} T+g z$ and $L_{v} q$ where $T$ is the absolute temperature, $C_{p a}$ the specific heat capacity at constant pressure, $g$ the gravitational acceleration, $z$ the height, $L_{v}$ the latent heat of vaporization and $q$ the specific humidity. Their sum is the moist static energy (MSE). The overturnings are computed from 5 years of daily snap-shots

2 Mass fluxes in the atmosphere and volume fluxes in the (Boussinesq) ocean 
(atmosphere) and 5-day averages (ocean). Note finally that $\Psi(S)$ includes both

Eulerian and (parameterized) eddy-induced transports.

\section{The coupled hydrological cycle}

3.1 The atmospheric branch

In all of our aqua-planet configurations $\Psi(M S E)$ is broadly similar in shape and magnitude, and similar to those previously discussed in the literature from both observations and atmospheric GCMs - e.g. Karoly et al (1997), Held and Schneider (1999), Czaja and Marshall (2006), and Pauluis et al (2008). Moreover, the decomposition of $\Psi(M S E)$ in DSE and $\mathrm{LH} / q$ components closely resembles that seen in the ERA-Interim re-analysis (see Döös and Nilsson, 2011). Here we focus on the atmospheric contribution to the hydrological cycle as encapsulated in $\Psi(q)$.

As can be seen in Fig. 3 (top), $\Psi(q)$ comprises two counter-rotating cells in each hemisphere. Note that high $q$ values correspond to the bottom of the troposphere. The dominant $(\sim 180 \mathrm{~Sv})$ mid-to-high latitude cells represent wet (dry) air parcels moving poleward (equatorward), and thus are associated with poleward moisture/LH transports from $20-30^{\circ}$ into the high-latitudes. These cells largely result from synoptic scale eddies (Döös and Nilsson, 2011). Poleward of $40^{\circ}$, the (surface) poleward branch of $\Psi(q)$ (typically between 1000-650 mb) is tilted upward, showing that air parcels gradually dry out as they move toward colder temperature (consistent with the Clausius-Clapeyron 
relationship). These streamlines are more tilted than the mean surface $q$ (thick solid). This suggests that air parcels are lifted off the ground and thus experience a more rapid cooling and drying than if they were moving along the surface. In our GCM, drying is mainly achieved through large-scale condensation in synoptic-scale weather systems. The return flow is nearly horizontal with dry $\left(\leq 2 \mathrm{~g} \mathrm{~kg}^{-1}\right)$ air parcels flowing equatorward in the upper troposphere. The mid-to-high latitude cell is closed between 20 and $30^{\circ}$ where air parcels "recharge" with moisture (downward arrow in $\Psi(q)$, Fig. 3 top). This moistening occurs through turbulent interaction with the boundary layer at latitudes where evaporation dominates over precipitation. Warm/moist outbreaks from lower latitudes play a primary role with poleward flow occurring at higher moisture than the mean surface value. In the tropics $\left(20^{\circ} \mathrm{S}-20^{\circ} \mathrm{N}\right)$, $\Psi(q)$ comprises 2 weak cells converging moisture on the Equator. These are mainly due to the time-mean Hadley circulation, with moist air flowing at low levels toward the Equator and dryer air flowing poleward aloft.

The atmospheric FWT scales as $\Delta q \Psi(q)$ with $\Delta q$ the moisture change between the poleward and equatorward branch (often $\Delta q \sim q_{s}$, the mean surface specific humidity). The pattern of $\Psi(q)$ evidently reflects the largescale E-P pattern (Fig. 3, middle). The fluxes of moisture into high latitudes and the deep tropics are matched by net precipitation while the moistening (downward branch of $\Psi(q)$ ) corresponds to net evaporation from the ocean surface. 
3.2 The oceanic branch

The streamfunctions in $S$-coordinates for our coupled simulations are shown in Figs. 3 (bottom) and 4. At the scaling level, $\Psi(S)$ is related to the ocean FWT, $F_{w}$, through $S_{o} F_{w} \simeq \Psi(S) \Delta S$ where $\Delta S$ is the salinity difference between the northward and southward flowing branch of the streamfunction. This is the freshwater analog of the relation between the (potential) temperature-coordinate streamfunction $\Psi(T)$ and the Ocean Heat Transport $H: H \sim \Psi(T) \Delta T$ (e.g. Czaja and Marshall, 2006). We now summarize key properties of our solutions (Figs. 3 bottom and 4)

The S-space circulation, $\Psi(S)$, has two counter-rotating cells in each hemisphere. A narrow cell is found at high salinity between 0 and $30^{\circ}$, transporting FW poleward from the deep tropics into the subtropics. In Aqua, where gyres are absent, these cells result from Ekman-driven subtropical overturning cells. They capture the poleward Ekman flow at the surface becoming saltier and the associated interior return flow. These cells are rather similar across all configurations, suggesting that they are mainly due to the vertical component of the wind-driven circulation even in the presence of gyral circulations.

The broader cell spans a large salinity and latitudinal range in each hemisphere and take on various forms and magnitude. Each transports FW from the high-latitudes into the subtropics. In Aqua, they are rather weak, especially at high-latitudes. This is the salt equivalent of the vanishing Deacon cell familiar in density coordinates (Döös and Webb, 1994), resulting from the cancellation between the wind and eddy-driven circulations. In Ridge, the presence of gyres 
is evident, notably the subpolar gyre near $50^{\circ}$. Deep water formation is seen in the northernmost part of the cell $\left(\sim 60^{\circ}\right)$ associated with a small salinity gradient and a horizontal (isohaline) equatorward flow at 34.5 psu.

To first order, Drake combines the SH of Aqua and the NH of Ridge although the asymmetry of the climate results in an interhemispheric cell in which northern deep waters are carried into the SH. In $S$-coordinates, the equatorward flow of deep water $(\sim 20-30 \mathrm{~Sv}$ confined within in a narrow range of salinity near $34.5 \mathrm{psu}$ ) manifests itself as an intense "horizontal" flow and a sharp transition in the streamfunction. Note the contrast between the large circulation at $60-70^{\circ} \mathrm{N}$ acting on a small salt contrast and the vanishingly small circulation near $60-70^{\circ} \mathrm{S}$ acting on a very large gradient. The Double-Drake set-up is characterized by the split of the northern clockwise cell into two cells, one for each basin. The saltier one, found in the small basin, is associated with deep water formation in this basin while the fresher one is dominated by contributions from wind-driven circulation in the large basin. This latter cell is more reminiscent of the form found in the zonally re-entrant southern ocean. As discussed elsewhere (Ferreira et al, 2015), the structure seen in DoubleDrake is similar to that found in ocean state estimates (e.g. the new ECCOv4 ocean state estimate; Forget et al, 2015) and is also consistent with inferences made from (sparse) hydrographic sections (see Talley, 2008). 
3.3 The ocean-atmosphere symmetry

The fact that both $\Psi(S)$ and $\Psi(q)$ are tightly linked to the E-P pattern results in the symmetry clearly evident in Fig. 3: poleward atmospheric moisture transport (counterclockwise cell) is associated with net precipitation on its poleward flank and net evaporation on its equatorward flank, and is matched with a clockwise salinity cell which transports freshwater equatorwards (and vice-versa).

The ocean-atmosphere symmetry is striking in Aqua but holds even in more complex geometries. The pattern of $\Psi(q)$ hardly changes across all simulations although its magnitude varies by about $\pm 20 \%$ (peak values are in the range $185 \pm 35 \mathrm{~Sv}$, not shown). The atmospheric FWT however varies by less than $\pm 7 \%$ (typically $1.6 \pm 0.1 \mathrm{~Sv}$ ). Because the atmospheric FWT is mostly eddy-driven, larger $\Psi(q)$ are associated with larger equator-to-pole temperature gradients and colder/drier mid-to-high latitudes. That is, variations of $\Psi(q)$ are partially compensated by variations of $q_{s}$ resulting in the FWT, which scales as $\Psi(q) \times q_{s}$, being relatively constant. On the ocean side, as seen previously in Figs. 3 and 4, $\Psi(S)$ for Drake, Ridge, and Double-Drake all exhibit 4 cells approximately sitting below the 4 atmospheric $\Psi(q)$ cells.

Our coupled simulations exhibit a wide range of climates and circulations: North-South symmetric states (Aqua and Ridge), a zonally re-entrant ocean with sea-ice (Drake-Double and Drake) or without sea-ice (Aqua), North-South asymmetry, and multiple basins with ocean gyres and deep connection. As such the ocean circulation and hence detailed FWT pathways, take on strikingly 
different forms. This is most obvious at high-latitudes where the FWT falls into two broad categories: a strong circulation $\Psi(S)$ with a small $\Delta S$ or a weak $\Psi(S)$ with a large $\Delta S$. The first regime is characteristic of zonally bounded convective basins while the second is typical of zonally re-entrant wind and eddy driven oceans. However, both regimes achieve the same meridional FWT. This is illustrated in Fig. 5 where $\Delta S$ is plotted against $\Psi(S)$ at $60^{\circ}$ for all the configurations (see caption for details). Both $\Psi(S)$ and $\Delta S$ vary by nearly one order of magnitude and yet the product $\Psi(S) \Delta S$ hardly varies at all. The thin line plotted in Fig. 5 maps out the $\Psi(S)$ and $\Delta S$ whose product is exactly constant and equal to the FWT demanded by the atmosphere at $60^{\circ} \mathrm{N}(0.25 \mathrm{~Sv}$ here).

As noted earlier, the atmospheric and oceanic FWT and associated E-P pattern remains nearly unchanged across our coupled solutions (Fig. 2). It is clear that ocean dynamics has little influence on the atmospheric FW/LH transport. The LH transport is primarily set by atmospheric dynamics: evaporation is large at the edge of the Hadley cell which transports moisture equatorward while synoptic eddies developing in the mid-latitude baroclinic zone transport moisture poleward where it is rained out following ClausiusClapeyron. The ocean responds passively to the atmospheric E-P pattern transporting what is demanded of it and takes on different forms depending on geometrical constraints and the climate state. There is little to suggest that the "coupled LH mode" is anything but a one way relationship. 
Before going on to our conclusions, we discuss a number of arguments that

296

- Oceans supply the heat required for evaporation. Our coupled simulations span a wide spectrum of climates, with polar sea surface temperatures varying from $10^{\circ} \mathrm{C}$ to freezing point (with sea ice cover). Similarly, the meridional Ocean Heat Transport varies greatly between configurations (for example from 0 to $1 \mathrm{PW}$ at $50^{\circ} \mathrm{N} / \mathrm{S}$, see Ferreira et al (2010)). Despite these very large ranges in available heat and supply by the ocean, the atmospheric LH/moisture transport varies little between configurations (as implied by the similarity of the E-P patterns, Fig. 2, top left). It is worth emphasizing that the evaporation patterns are very similar across the configurations. A notable exception is where sea ice is present/absent. In this case, differences in evaporation locally peak at $0.8 \mathrm{~mm} /$ day as evaporation is severely limited by the cold temperatures and the capping effect of sea ice. However, this effect is largely compensated by a reduction in precipitation and the E-P change (and thus the moisture transport) remains relatively small. Even in this favorable limit where the ocean has a large impact on E, negative feedbacks strongly limit its ability to influence the atmospheric moisture/LH transport. This suggests that the heat supplied by the ocean is not a critical factor in controlling the atmospheric $\mathrm{LH}$ transport. 
- Ocean processes such as salt barriers regulate the moisture flux to the atmosphere. Masson et al (2005) suggested that salt barriers (formed by precipitation) could have a strong impact on SSTs and precipitation, pointing to an oceanic feedback on atmospheric moisture flux. These effects, however, appear to be very localized to the Equatorial region and unlikely to have a large scale impact.

- Effects of the Goldsbrough circulation. The Goldsbrough circulation is the barotropic ocean circulation induced by the surface mass flux (EP). Huang and Schmitt (1993) estimate the magnitude of this circulation in the range $0.5-1.5 \mathrm{~Sv}$. Assuming that this circulation acts on a EastWest temperature gradient $\Delta T$ of about $2^{\circ} \mathrm{C}$, its meridional transport is $\rho_{o} C_{p} \Psi_{\text {Gold }} \Delta T \sim 0.012 \mathrm{PW}$, a very small number unlikely to have a sizeable climatic impact. It is worth emphasizing that the ocean component of our coupled model uses real freshwater boundary conditions and thus includes the physics associated with the Goldsbrough circulation.

- The coupled simulations are rather idealized, notably in their representation of the deep overturning circulation and internal mixing. Morerever, our ocean model employs a constant vertical mixing coefficient. Observations suggest that abyssal mixing varies greatly in space (i.e. Polzin et al, 1997) although thermocline values appear uniformly low (Ledwell et al, 1993, 2011). The dependance of the FWT on mixing is unclear. To test the possible sensitivity of the FWT to mixing, we carried out a Double-Drake experiment with increased diapycnal mixing at depth following Bryan and Lewis 
(1979) (an arctangent profile with diffusivities increasing from $3 \times 10^{-5}$ in the thermocline to $10^{-4} \mathrm{~m} \mathrm{~s}^{-2}$ at the bottom). Changes to FWT are very small, less than 0.04Sv. Ferrari and Ferreira (2011) showed that abyssal mixing had a small impact on the ocean heat transport although it did change the strength of the deep overturning cells. This is because the deep temperature gradients over which these cells act are weak. In respect of the FWT, the salinity gradients in the ocean compensate for changes in the circulation to ensure that the ocean FWT balances the pattern of E-P.

Nonetheless the idealized nature of our coupled simulations is a caveat and warranties further investigations with more complex models.

\section{Conclusions}

We have explored the dynamics of FWT in the coupled ocean-atmosphere system using a series of idealized coupled simulations. To this end, we introduce streamfunctions in salt- and specific humidity-coordinates. Both present the dynamics of FWT in their respective realms.

The symmetry of the ocean and atmosphere FWT is clearly revealed in the symmetry of $\Psi(q)$ and $\Psi(S)$, encapsulating the transformation and exchange of freshwater in the coupled system. This is why the FWT and the atmospheric LH transport are sometimes described as "coupled ocean-atmosphere modes". However $\Psi(S)$ reveals that fundamentally different modes of ocean FWT dynamics can exist under very similar E-P conditions. Two limit cases were identified: 1) a large circulation/small salt stratification mode typical of 
regions of deep water formation and 2) a weak circulation/large stratification mode found in zonally re-entrant regions. The ocean FWT dynamics does not impact the atmospheric moisture transport: the ocean FWT is essentially passive in this "coupled mode". Instead, the necessary ocean FWT is set to first order by atmospheric dynamics. The ocean circulation and salinity stratification adjust to this imposed boundary condition in different ways depending on the geometrical constraints. In other words, the atmospheric freshwater is returned "for free" with the ocean adjusting its $\Psi(S)$ and $\Delta S$ to match $F_{w}$ : slow ocean circulation leading to a large salinity contrast and vice-versa.

Our conclusions will not come as a surprise to atmospheric scientists. The term "coupled mode" used to described the atmospheric LH transport appears in the oceanographic literature. We argue that this term puts an undeserved emphasis on the ocean in a phenomenon which is essentially the results of dynamics internal to the atmosphere. It is worth underscoring that our conclusions are limited to the steady state case. It is unclear whether the ocean FWT takes a more active role in a transient climate change in which, for example, the climate system is subject to a forcing perturbation. Another limitation is that our simulations do not cover the full range of climate states suggested by the paleoclimate record, which shows that Earth has experienced Snowball and hothouse climates. Although it seems unlikely that the ocean would take a more active role in the warm climate limit, this may not be true in very cold climates with extensive sea ice cover. 
Finally, we would like to emphasize that our conclusions do not imply that there is little interest in studying the oceanic FWT and salinity distribution. In fact, the passive nature of the ocean in this respect makes it a particular efficient "tape recorder" of changes in the hydrological cycle.

Acknowledgements The authors would like to thank Richard Greatbatch for advice and encouragements over the years. His openness, wide interest and enthusiasm for all matters Atmosphere and Ocean is an example to all of us. We thank the Physical Oceanography program of NSF

\section{References}

Adcroft A, Campin JM (2004) Re-scaled height coordinates for accurate representation of free-surface flows in ocean circulation models. Ocean Modell $7: 269-284$

Adcroft A, Campin J, Hill C, Marshall J (2004) Implementation of an atmosphere-ocean general circulation model on the expanded spherical cube. Mon Wea Rev 132:2845-2863

Bryan K, Lewis LJ (1979) A water mass model of the world ocean. J Geophys Res 84:2503-2517

Bryden H, Imawaki S (2001) Ocean heat transport. In: Siedler G, Church J, Goulds J (eds) Ocean Circulation and Climate, Academic Press, pp 455-474 Campin JM, Marshall J, Ferreira D (2008) Sea ice-ocean coupling using a rescaled vertical coordinate $z^{\star}$. Ocean Modell 24:1-14 
Czaja A, Marshall JC (2006) The partitioning of poleward heat transport between the atmosphere and ocean. J Atmos Sci 63:1498-1511

Döös K, Nilsson J (2011) Overturning analysis of the meridional energy transport in the atmosphere. J Atmos Sci 68:1806-1820

Döös K, Webb DJ (1994) The Deacon Cell and the other meridional cells in the Southern Ocean. J Phys Oceanogr 24:429-442

Durack PJ, Wijffels SE (2010) Fifty-year trends in global ocean salinities and their relationship to broad-scale warming. J Climate 23:4342-4362

Enderton D, Marshall J (2009) Explorations of atmosphere-ocean-ice climates on an aqua-planet and their meridional energy transports. J Atmos Sci 66:1593-1611

Ferrari R, Ferreira D (2011) What processes drive the ocean heat transport? Ocean Modell 38:171-186

Ferreira D, Marshall J, Campin JM (2010) Localization of deep water formation: role of atmospheric moisture transport and geometrical constraints on ocean circulation. J Climate 23:1456-1476

Ferreira D, Marshall J, Rose B (2011) Climate determinism revisited: multiple equilibria in a complex climate model. J Climate 24:992-1012

Ferreira D, Marshall J, Forget G (2015) On the dynamics of the oceanic feshwater transport. In preparation

Forget G, Campin JM, Heimbach P, Hill C, Ponte R, Wunsch C (2015) Ecco version 4: an integrated framework for non-linear inverse modeling and global ocean state estimation. Geoscientific Model Development Submitted 
Gent PR, McWilliams JC (1990) Isopycnic mixing in ocean circulation models.

Held I, Schneider T (1999) The surface branch of the zonally averaged mass transport circulation in the troposphere. J Atmos Sci 56

Held I, Soden BJ (2006) Robust responses of the hydrological cycle to global warming. J Climate 19:5686-5699

Huang RX, Schmitt RW (1993) The goldsbrough-stommel circualtion of the world oceans. J Phys Oceanogr 23:1277-1284

Karoly DJ, McInosth PC, Berrisford P, McDougall TJ, Hirstt AC (1997) Similarity of the Deacon cell in the southern ocean and Ferrel cells in the atmosphere. Quart J Roy Meteor Soc 123

Klinger BA, Marshall J, Send U (1996) Representation of convective plumes by vertical adjustment. J Geophys Res C8(101):18,175-18,182 Ledwell JR, Watson AJ, Law C (1993) Evidence for slow mixing across the pycnocline from an open-ocean tracer-release experiment. Nature 364:701703

${ }_{444}$ Ledwell JR, St Laurent LC, Girton JB, Toole JM (2011) Diapycnal Mixing in

445 the Antarctic Circumpolar Current. J Phys Oceanogr 41:241-246 Lumpkin R, Speer K (2007) Global ocean meridional overturning. J Phys Oceanogr 37:2250-2562

${ }_{448}$ Marshall J, Plumb RA (2008) Atmosphere, Ocean and Climate Dynamics: An Introductory Text, International Geophysics Series, vol 93. Elsevier Academic Press 
Marshall J, Adcroft A, Hill C, Perelman L, Heisey C (1997a) A finite-volume, incompressible navier stokes model for studies of the ocean on parallel computers. J Geophys Res 102(C3):5753-5766

Marshall J, Hill C, Perelman L, Adcroft A (1997b) Hydrostatic, quasi-hydrostatic, and nonhydrostatic ocean modeling. J Geophys Res 102(C3):5733-5752

Marshall J, Adcroft A, Campin JM, Hill C, White A (2004) Atmosphere-ocean modeling exploiting fluid isomorphisms. Mon Wea Rev 132:2882-2894

Marshall J, Ferreira D, Campin J, Enderton D (2007) Mean climate and variability of the atmosphere and ocean on an aquaplanet. J Atmos Sci 64:42704286

Masson S, Luo JJ, Madec G, Vialard J, Durand F, Gualdi S, Guilyardi E, Behera S, Delecluse P, Navarra A, Yamagata T (2005) Impact of barrier layer on winter-spring variability of the southeastern Arabian Sea. Geophys Res Lett 32:L07,703

Molteni F (2003) Atmospheric simulations using a GCM with simplified physical parametrizations. I: model climatology and variability in multi-decadal experiments. Climate Dyn 64:175-191

Pauluis O, Czaja A, Korty R (2008) The global atmospheric circulation on moist isentropes. Science 321:1075

Polzin KL, Toole JM, Ledwell JR, Schmitt RW (1997) Spatial variability of turbulent mixing in the abyssal ocean. Science 276(5309):93-96 
Redi MH (1982) Oceanic isopycnal mixing by coordinate rotation. J Phys Oceanogr 12:1154-1158

Rhines P, Häkkinen S, Josey SA (2008) Is the oceanic heat transport significant in the climate system? In: R R Dickson et al (ed) Arctic-Subarctic Ocean Fluxes, Springer, pp 87-109

Saenko OA, Merryfield WJ (2006) Vertical partition of ocean heat transport

479 in isothermal coordinates. Geophys Res Lett 33:L01,606

Talley LD (2008) Freshwater transport estimates and the global overturning circulation: Shallow, deep and throughflow components. Progress in Oceanography 78:257-303

Wijffels SE (2001) Ocean freshwater transport. In: Siedler G, Church J, Goulds J (eds) Ocean Circulation and Climate, Academic Press, pp 475-488

${ }_{485}$ Winton M (2000) A reformulated three-layer sea ice model. J Atmos Oceanic

Technol 17:525-531 


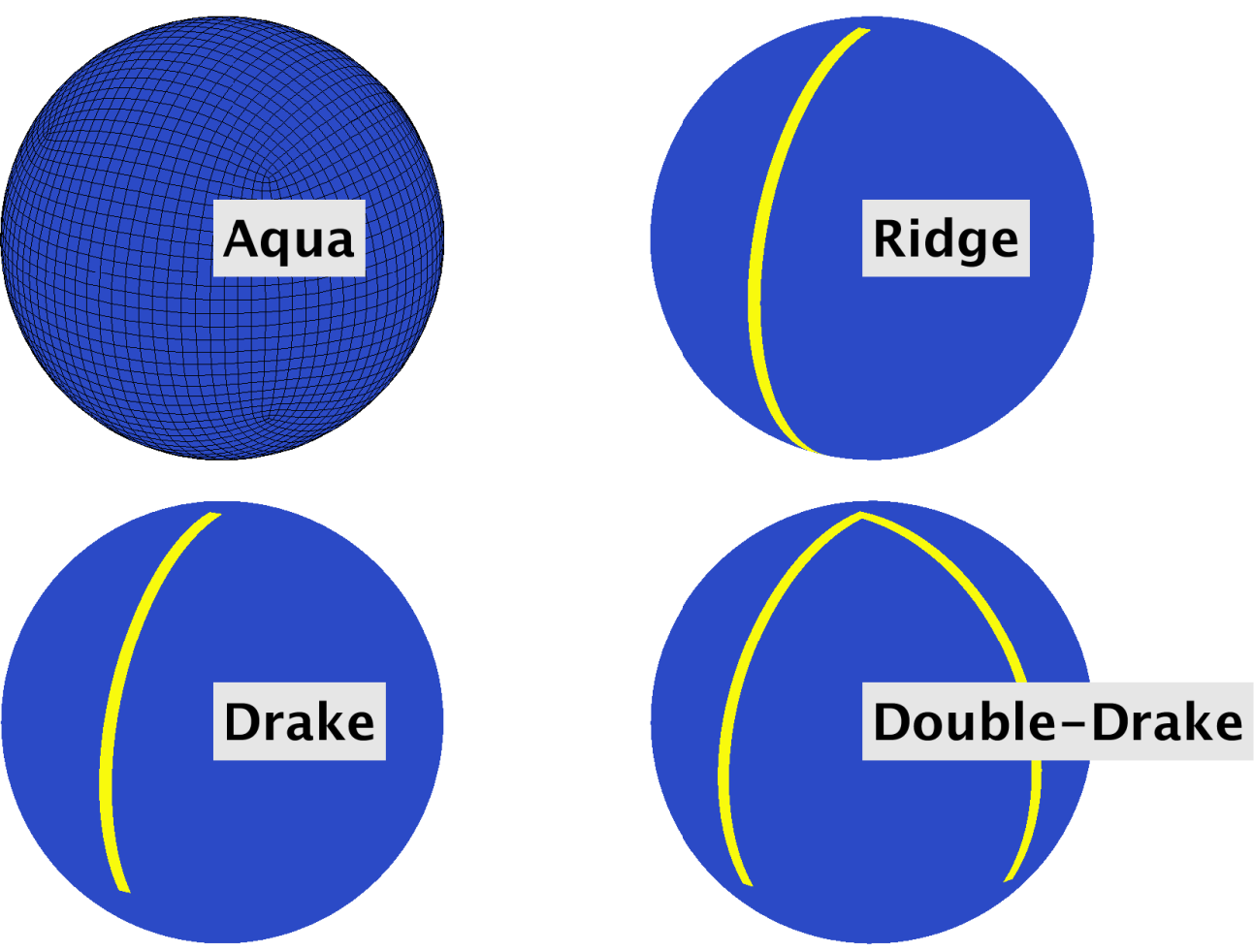

Fig. 1 The four continental configurations used in the present study. Yellow shading denotes the continental barriers extending from the flat bottomed ocean at $3000 \mathrm{~m}$ depth to the ocean surface. The cube-sphere mesh is indicated in the pure Aquaplanet configuration (top left). 

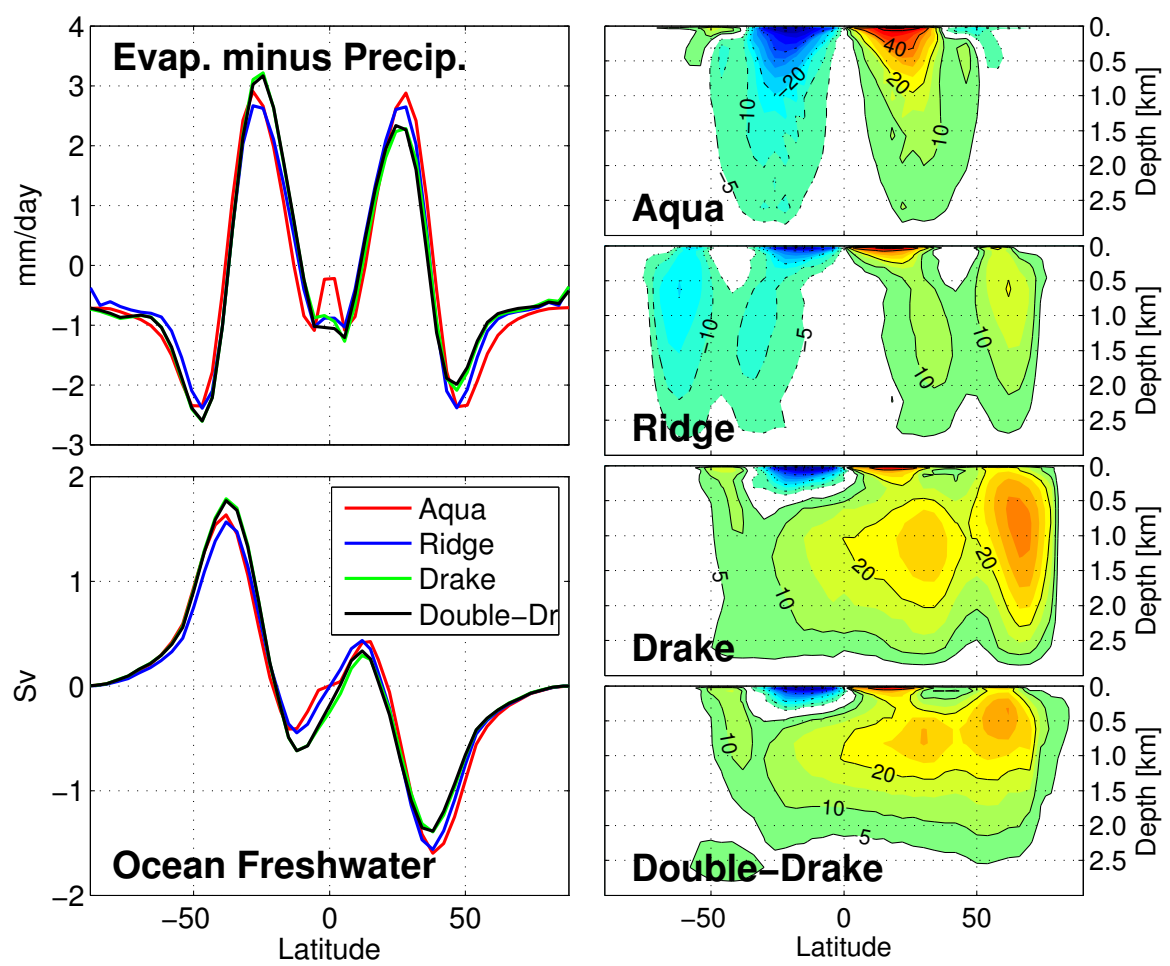

Fig. 2 Left: (top) Zonal- and time-average of Evaporation minus Precipitation (in mm/day) and (bottom) time-average ocean FWT (in Sv) for Aqua, Ridge, Drake and Double-Drake. Right: Residual-mean MOC (in Sv), the sum of the Eulerian and (parameterized) eddy overturnings. Clockwise and counterclockwise circulations are denoted by red and blue shadings, respectively. 

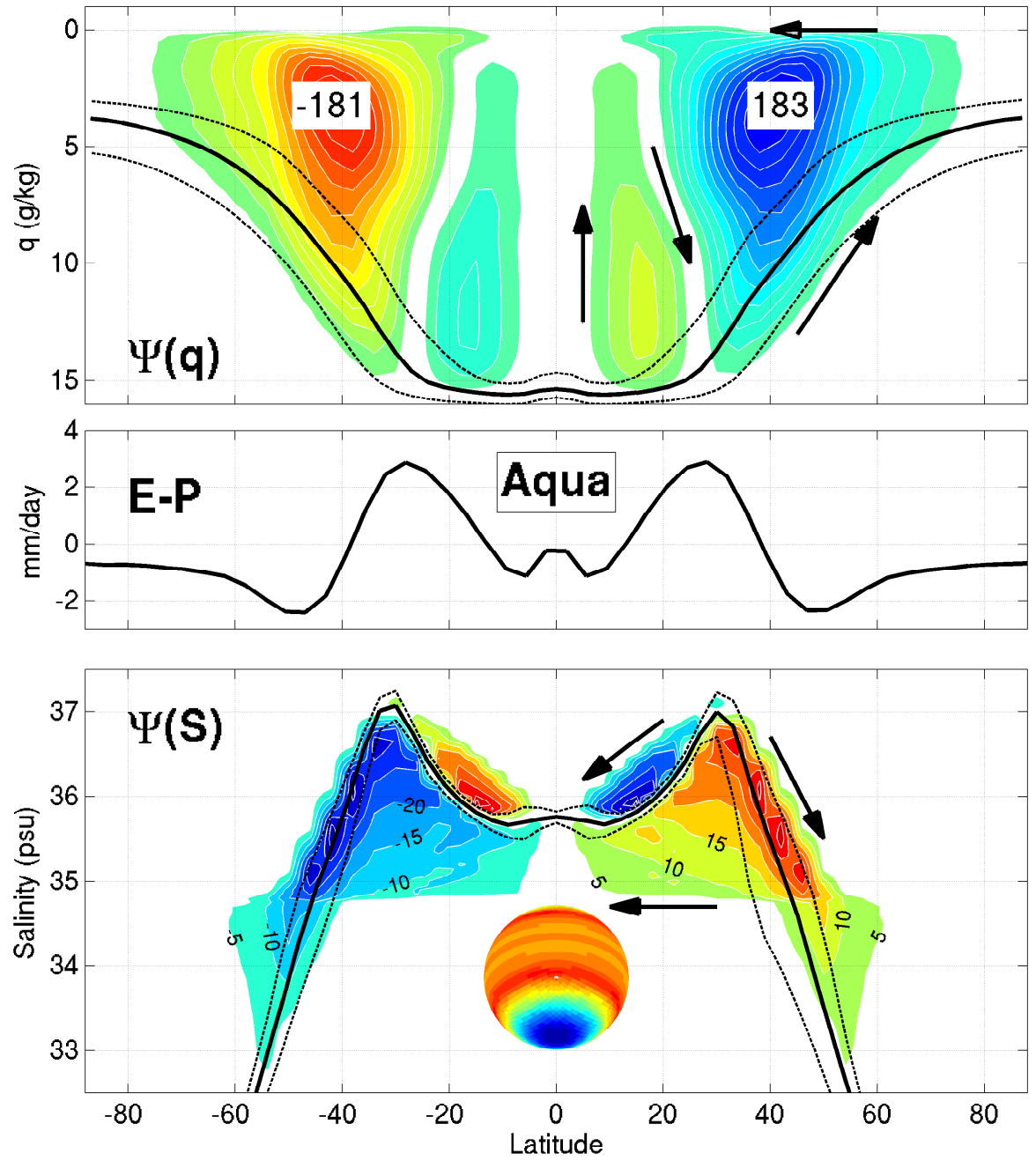

Fig. 3 The coupled hydrological cycle in Aqua: (top) $\Psi(q)$ for the atmosphere, (middle) E-P (mm/day) and (bottom) $\Psi(S)$ for the ocean. Clockwise and counter-clockwise circulations are shown in red and blue shadings, respectively. The median value (thick solid) and the $90 \%$ and $10 \%$ percentiles (dashed black) of the surface specific humidity (top) and sea surface salinity (bottom) are plotted. The SSS distribution of Aqua is shown in the bottom panel. 

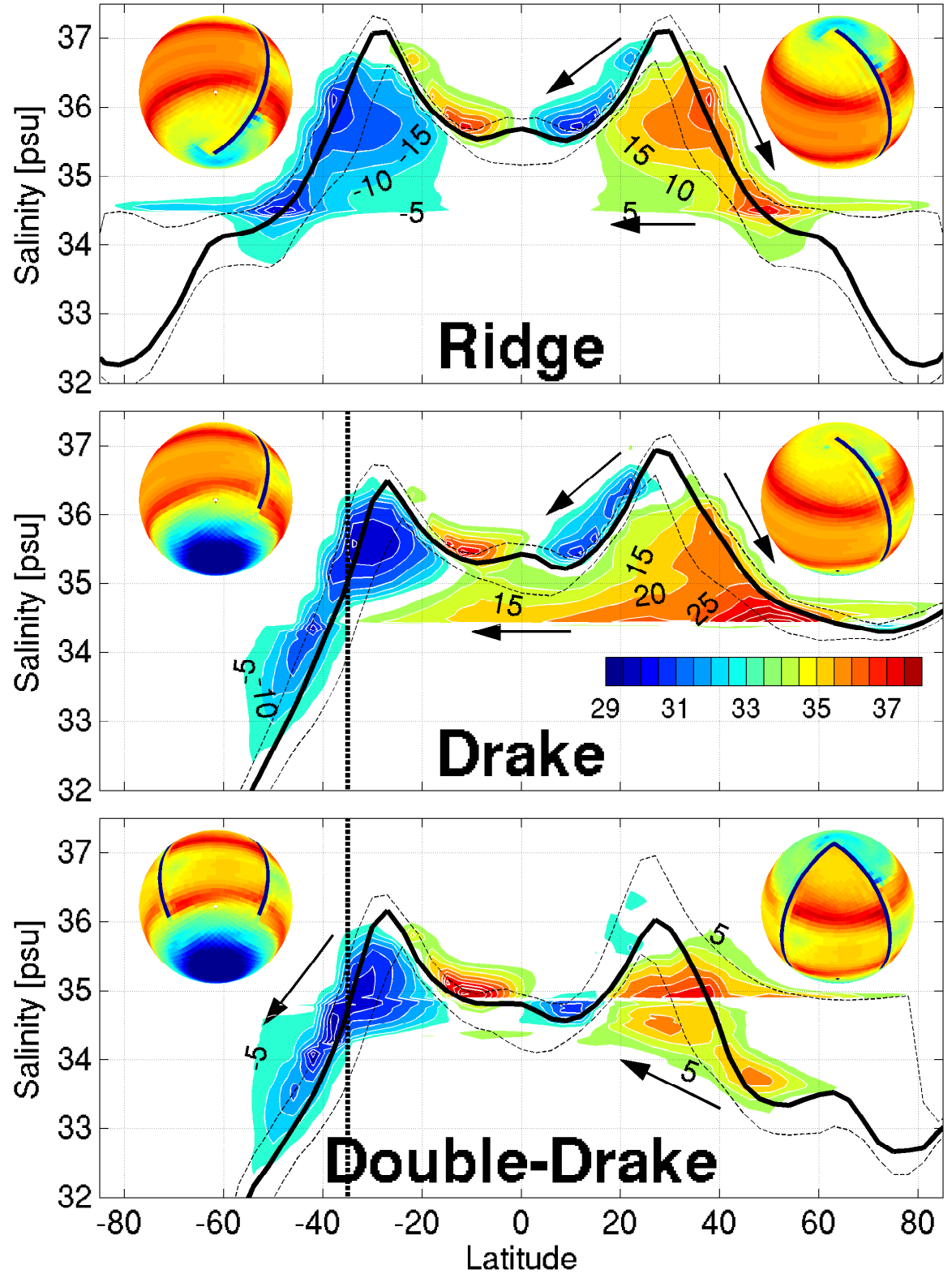

Fig. $4 \Psi(S)$ for (top) Ridge, (middle) Drake and (bottom) Drake-Double (in Sv). See bottom panel of Fig. 3 for details. The thick dashed line in the middle and bottom panel indicates the southern limit of the land barrier $\left(35^{\circ} \mathrm{S}\right)$. Globes in each panel show the annual mean SSS distributions (the associated colorbar is found in the middle panel). 


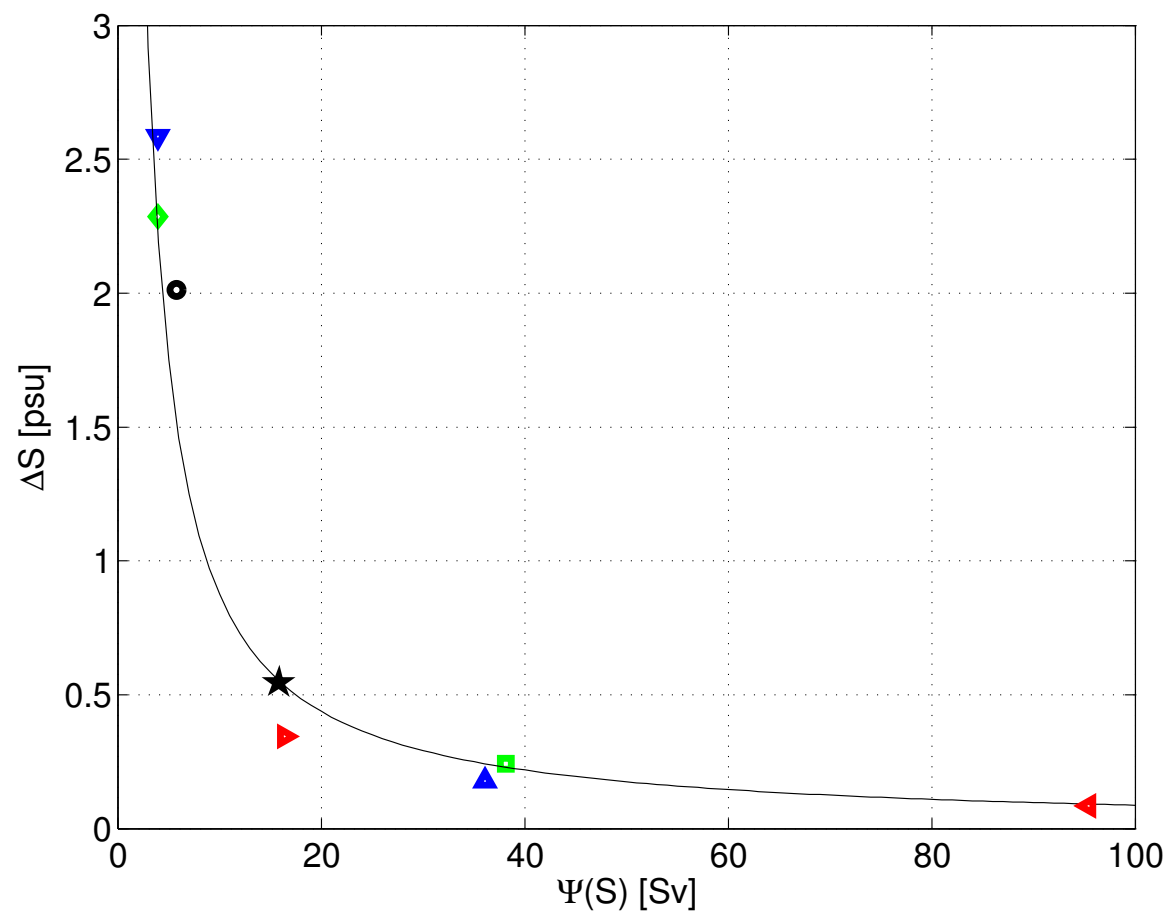

Fig. 5 Plot of the $\Delta S$ (psu) as a function of magnitude of $\Psi(S)(\mathrm{Sv})$ at $60^{\circ}$ of latitude for Aqua (black circle), Ridge (black star), Northern (green square) and Southern (green diamond) hemispheres of Drake, the Northern (blue triangle up) and Southern (blue triangle down) hemispheres of Double-Drake, the Northern Large (red triangle right) and Small (red triangle left) basins of Double-Drake. The magnitude of $\Psi(S)$ is the sum of all poleward volume transports while $\Delta S$ is the averaged salinity of poleward flows minus the averaged salinity of equatorward flows. To account for the width of the Large $\left(270^{\circ}\right)$ and Small $\left(90^{\circ}\right)$ basins of Double-Drake, their $\Psi$ are rescaled by factors $4 / 3$ and 4 , respectively. The thin solid line is a plot of $\Psi(S) \Delta S=F_{w} S_{o}$ a constant, given by $S_{o}=35$ psu and $F_{w}=0.25 \mathrm{~Sv}$, a typical value of $\mathrm{FWT}$ at $60^{\circ} \mathrm{N}$ in all configurations (see Fig. 2, bottom left). 